See discussions, stats, and author profiles for this publication at: https://www.researchgate.net/publication/233126049

\title{
Surge damping analysis in pipe systems: Modelling and experiments
}

Article in Journal of Hydraulic Research · December 2010

DOI: 10.1080/00221686.2004.9641209

\section{CITATIONS}

119

4 authors, including:

$$
\text { Helena M. Ramos }
$$

11. University of Lisbon

235 PUBLICATIONS 4,872 CITATIONS

SEE PROFILE

(20) Dália Loureiro

National Laboratory for Civil Engineering

67 PUBLICATIONS 478 CITATIONS

SEE PROFILE

Some of the authors of this publication are also working on these related projects:

REDAWN: Reducing the Energy Dependency of Atlantic Area Networks View project

Water protection after tympanostomy tubes View project 


\title{
Surge damping analysis in pipe systems: modelling and experiments
}

\section{Effet d'atténuation du coup de bélier dans les systèmes de conduits: modelation mathématique et expériences}

\author{
HELENA RAMOS, Department of Civil Engineering, Instituto Superior Técnico (IST), Av. Rovisco Pais, \\ 1049-001 Lisboa,Portugal.E-mail:hr@civil.ist.utl.pt; didia@civil.ist.utl.pt
}

DÍDIA COVAS, Department of Civil Engineering, Instituto Superior Técnico (IST), Av. Rovisco Pais, 1049-001 Lisboa, Portugal. E-mail: didia@civil.ist.utl.pt

ALEXANDRE BORGA, Department of Civil Engineering, Instituto Superior de Engenharia de Lisboa (ISEL), Portugal. E-mail: aborga@sapo.pt

DÁLIA LOUREIRO, National Lab of Civil Engineering (LNEC), Av. do Brasil 101, 1799 Lisboa, Portugal. E-mail: dloureiro@lnec.pt

\begin{abstract}
The current study focuses on the analysis of pressure surge damping in single pipeline systems generated by a fast change of flow conditions. A dimensionless form of pressurised transient flow equations was developed, presenting the main advantage of being independent of the system characteristics. In lack of flow velocity profiles, the unsteady friction in turbulent regimes is analysed based on two new empirical correctivecoefficients associated with local and convective acceleration terms. A new surge damping approach is also presented taking into account the pressure peak time variation. The observed attenuation effect in the pressure wave for high deformable pipe materials can be described by a combination of the non-elastic behaviour of the pipe-wall with steady and unsteady friction effects. Several simulations and experimental tests have been carried out, in order to analyse the dynamic response of single pipelines with different characteristics, such as pipe materials, diameters, thickness, lengths and transient conditions.

\section{RÉSUMÉ}

Cette étude se concentre sur l'analyse de l'atténuation du coup de bélier dans les systèmes simples des conduites produits par une rapide changement des états d'écoulement. Les équations d'adimensionnel d'écoulement pressurisées en régime transitoire a été développée, présentant l'avantage principal d'être indépendante des caractéristiques de système. Dans le manque de profils de vitesse d'écoulement, l'évaluation du coefficient de résistance dans des régimes turbulents a été analysée avec deux nouveaux affaiblissements coefficients empiriques, qui affectent des paramètres d'accélération locale et convective. Une nouvelle approche des curves atténuant est présentée tenant compte de la variation de pression au long du temps. L'effet d'atténuation peut être une combinaison du comportement non élastique du conduit, de l'effet du facteur résistant dans les régimes permanents et variables. Plusieurs simulations et essais expérimentaux ont été effectués, afin d'examiner la réponse dynamique des pipes simples avec différents matériaux des conduits, diamètres, longueurs et conditions de fonctionnement.
\end{abstract}

Keywords: Surge damping, energy dissipation, elastic or non-elastic behaviour, pressure oscillations.

\section{Introduction}

Waterhammer analysis usually focuses on the estimation of the extreme pressures associated with the worse case scenarios. Valves manoeuvres, pumps trip-off and start-up, turbines stoppage and pipe accidental burst are typical events that generate fluid transients considered in the design of pipe systems. Even though the type of actions which induce stronger effects on the pressure variation are well known, the correct prediction of the pressure wave propagation, in particular, the damping effect, is not always properly accounted for, which will influence the system re-operation, advanced model calibration and analysis of dynamic behaviour of the system response.

The need of a more reliable analysis of the pressure wave propagation as well as a better understanding of physical phenomena was the major motivation of the current research work. This study consists of the development of theoretical formulations, based on both experimental tests and computer modelling, to characterize the pressure surge damping. According to the type of the system or the accuracy required, different hydraulic transient simulators can be used. However, transient solvers commercially available in the market are not capable of predicting the pressure 
surge damping observed in real systems. Since water pipe systems are expensive infrastructures, computational modelling is easily available, even though with important constraints and limitations associated with inevitable simplified assumptions. Up to now, the waterhammer modelling rarely takes into account all the important waterhammer parameters that significantly influence the system's response. Whilst, in some cases, these effects can be neglected with no loss of accuracy, under certain circumstances and depending on the type of analysis required, the error can be unacceptable.

From the practical point of view, engineers must be able to estimate the time pressure variation and understand the physical phenomena associated with transients that occur between two steady state operating conditions, even without advanced and complex models currently developed by researchers. Several factors can contribute for pressure surge damping (Covas et al., 2003), such as the non-elastic rheological behaviour of the pipe material, presence of free gas in the fluid, leaks or ruptures, pipe movement or shear stress in pipe-walls.

\section{State-of-the-art}

Classical waterhammer models, which normally assume linearelastic behaviour of the pipe-walls and quasi-steady state friction losses, have been widely used and presented in expert literature (Chaudhry, 1987; Almeida and Koelle, 1992; Wylie and Streeter, 1993). However, recently research work has changed this tendency. Relevant developments in inverse transient analysis have been achieved recently, in which the dynamic behaviour of the pipe system during a transient event has been used for model calibration and leak detection (Covas and Ramos, 1999, 2001; Covas et al., 2001, 2002c; Covas, 2003). Furthermore, the future perspective of plastic pipes has recently induced the development of more accurate hydraulic transient models taking into account the viscoelastic behaviour of these materials (Gally et al., 1979; Rieutford and Blanchard, 1979; Covas et al., 2002a,b; Pezzinga, 2002b; Covas, 2003).

Comparisons between experimental and computational results using the Method of Characteristics (MOC) enhance some effects that can be identified as the main sources of surge damping. Three types of models have been proposed in literature to describe fast transient events and to help the identification of dynamic effects: (i) the quasi-steady state $1 \mathrm{D}$ model with a pseudo-uniform velocity distribution in each cross-section, linear elastic behaviour of the pipe material and pipe constrained from any axial or lateral movements, is well-known for underestimating friction forces and overestimating pressure oscillations (Chaudhry, 1987; Almeida and Koelle, 1992; Wylie and Streeter, 1993); (ii) an equivalent model to (i), with a modification in friction factor is implemented by adding the unsteady-friction effect due to the non-uniformity of velocity profiles that includes both the effects of local inertia and unsteady wall shear stress on flow, which several approximate formulas have been presented (Zeilke, 1968; Trikha, 1975; Hino et al., 1977; Brunone et al., 1991, 1995; Vardy et al., 1993); (iii) the incorporation of the viscoelastic behaviour of plastic pipe-walls in the transient-flow equations (Rieutford and Blanchard, 1979; Gally et al., 1979; Covas et al., 2002a,b). Dynamic effects of type (ii) and (iii) seem to be very difficult to distinguish as both contribute to the surge damping and phase shift of the pressure wave.

Fluid flow in a pipeline is essentially of one-dimensional flow type (1D). Zeilke (1968) proposed a formulation relating the shear stress at the pipe-wall, in transient laminar flow, with the instantaneous mean velocity and weighted past velocity changes. Trikha (1975) simplified Zeilke's model using exponential relations for simulating frequency dependent friction. More recently, Brunone et al. (1991) proposed a formula to evaluate unsteady friction losses with a decay coefficient $\left(k_{3}\right)$ related to the velocity distribution in the cross-section. Vitkovsky et al. (2000) proposed changes to the unsteady-friction model, which produce more damping and a slight positive shift in the pressure oscillation phase.

In 2D models, the unsteady-friction factor is estimated considering the radial variation of flow characteristics. Developments presented by Bratland (1986), Vardy and Hwang (1991), SilvaAraya and Chaudhry (1997), Pezzinga (1999) and Abreu and Almeida (2000) analysed different approaches based on velocity profiles for each pipe section and time. Covas et al. (2002b) and Pezzinga (2002b) present results of an experimental and theoretical study for a high-density polyethylene (HDPE) additional pipe, allowing the analysis of both linear elastic and Kelvin-Voigt viscoelastic behaviour of the pipe material. Pezzinga (2002b) also compared both one-dimensional (1D) and quasi-2D flow models. The numerical results showed that the viscoelastic model better describes the surge damping in plastic pipes, the elastic model adequately estimates the maximum and minimum oscillations by the first peaks, and the difference between 1D and 2D was not significant.

\section{Flow model}

\subsection{Basic equations}

Considering the flow mainly one-dimensional (1D), hydraulic transients in pressurised pipe systems can be satisfactorily described by a linear elastic model, according to the following assumptions (Chaudhry, 1987; Pejovic et al., 1987; Almeida and Koelle, 1992; Wylie and Streeter, 1993): (i) the flow is considered with a pseudo-uniform velocity profile in each cross-section; (ii) the fluid is assumed one-phase, homogeneous, compressible and negligible temperature and density changes; (iii) the rheological behaviour of the pipe material is linear-elastic; (iv) the pipe is a straight uniform element without lateral inflow or outflow; (v) the pipe is completely constrained from movement.

Any disturbance induced in the flow is propagated with a wave speed that will strongly influence the dynamic response in the pipeline. The elastic wave speed corresponds to the storage capacity of the fluid compressibility and pipe deformation:

$$
c=\sqrt{\frac{K}{\rho[1+(K / E) \psi]}}
$$


in which $E=$ Young's modulus of elasticity of the pipe $(\mathrm{Pa})$; $K=$ fluid bulk modulus of elasticity $(\mathrm{Pa}) ; \rho=$ fluid density $\left(\mathrm{kg} / \mathrm{m}^{3}\right) ; \psi=$ dimensionless parameter that takes into account the cross-section parameters of the pipe and conduit constraints (Chaudhry, 1987; Wylie and Streeter, 1993).

Pressure transients in pipe systems are usually described by the well-known waterhammer equations - the continuity and momentum equations. In most engineering applications, the convective acceleration terms $(Q \partial Q / \partial x$ and $Q \partial H / \partial x)$ are negligible and the basic differential equations of unsteady pressurised flows, can be further simplified to a hyperbolic system of equations (Chaudhry, 1987; Wylie and Streeter, 1993; Ramos, 1995) which can be presented in matrix form as follows (Ramos, 1995; Ramos et al., 2000; Ramos and Almeida, 2001):

$$
\frac{\partial U}{\partial t}+\frac{\partial F(U)}{\partial x}=D(U)
$$

yielding the following vectors:

$$
\begin{aligned}
U & =\left[\begin{array}{c}
H \\
Q
\end{array}\right] \quad F(U)=\left[\begin{array}{c}
\frac{c^{2}}{g A} Q \\
g A H
\end{array}\right] \\
D(U) & =\left[\begin{array}{c}
0 \\
-\frac{J g A}{Q^{2}} Q|Q|
\end{array}\right]
\end{aligned}
$$

where $x=$ distance along the pipe axis (m); $t=$ time (s); $A=$ cross-section flow area $\left(\mathrm{m}^{2}\right) ; Q=$ discharge $\left(\mathrm{m}^{3} / \mathrm{s}\right)$; $H=$ piezometric head $(\mathrm{m}) ; J=$ hydraulic gradient $(-)$; $g=$ gravitational acceleration $\left(\mathrm{m} / \mathrm{s}^{2}\right) ; c=$ wave speed $(\mathrm{m} / \mathrm{s})$.

This set of equations can be solved by several numerical methods (implicit or explicit finite differences, finite elements, boundary elements, or MOC), being the MOC, the finite-difference method adopted in this case. For the solution of 1D hydraulic transients, MOC has become extensively used, having proven to be better than other methods due to easiness programming and efficiency of results. The partial derivatives are replaced by finite difference approximations. However, the stability conditions restrict the time and the space step to Courant-Friedrich-Lewy verification,

$$
\frac{\Delta x}{\Delta t} \geq \pm c
$$

that is equivalent to neglecting the kinetic fluid term when compared to the wave speed propagation $(V \ll c)$, leading to straight characteristic lines in time and space that constitute the computational grid as shown in Fig. 1. Ideally, it should be an equality to avoid numerical dispersion and damping, i.e. $\Delta x / \Delta t= \pm c$ due to numerical interpolations. By transforming the set of partial differential equations into a set of ordinary differential equations valid along the characteristic lines, and integrating in the $x-t$ plane, the finite difference schemes can be written as follows (Borga, 1986; Ramos, 1995):

$$
\begin{aligned}
& C^{+}: H_{\mathrm{P}}-H_{\mathrm{A}}+\frac{c}{g A}\left(Q_{\mathrm{P}}-Q_{\mathrm{A}}\right)+I^{+}=0 \\
& C^{-}: H_{\mathrm{P}}-H_{\mathrm{B}}-\frac{c}{g A}\left(Q_{\mathrm{P}}-Q_{\mathrm{B}}\right)+I^{-}=0
\end{aligned}
$$

Several numerical techniques can be used to integrate the term $I^{ \pm}$, which represents the friction losses. In this paper, this term was evaluated by a first order explicit scheme or a second order implicit approximation as follows:

First order explicit scheme

$$
\begin{aligned}
& I^{+}=R\left|Q_{\mathrm{A}}\right| Q_{\mathrm{A}} \\
& I^{-}=-R\left|Q_{\mathrm{B}}\right| Q_{\mathrm{B}}
\end{aligned}
$$

Second order implicit scheme

$$
\begin{aligned}
& I^{+}=R\left|Q_{\mathrm{P}}\right| Q_{\mathrm{P}} \\
& I^{-}=-R\left|Q_{\mathrm{P}}\right| Q_{\mathrm{P}}
\end{aligned}
$$

in which $R=J \Delta x / Q^{2}=\Delta H_{0} / N Q^{2}$ and $N=$ the number of pipe elements.

In order to obtain a generic formulation applicable to any system characteristics, the use of dimensionless parameters of relative head, $h$, relative head losses, $\Delta h_{0}$, and relative discharge, $q$, is considered:

$$
h=\frac{H}{c Q_{0} / g A}=\frac{H}{\Delta H_{\mathrm{J}}} ; \quad \Delta h_{0}=\frac{\Delta H_{0}}{\Delta H_{\mathrm{J}}} ; \quad q=\frac{Q}{Q_{0}} .
$$

For a first order integration of head losses, Eq. (5) can be transformed into a set of dimensionless equations:

$$
\begin{aligned}
& C^{+}: h_{\mathrm{P}}-h_{\mathrm{A}}+q_{\mathrm{P}}-q_{\mathrm{A}}+\frac{\Delta h_{0}}{N}\left|q_{\mathrm{A}}\right| q_{\mathrm{A}}=0 \\
& C^{-}: h_{\mathrm{P}}-h_{\mathrm{B}}-q_{\mathrm{P}}+q_{\mathrm{B}}-\frac{\Delta h_{0}}{N}\left|q_{\mathrm{B}}\right| q_{\mathrm{B}}=0
\end{aligned}
$$
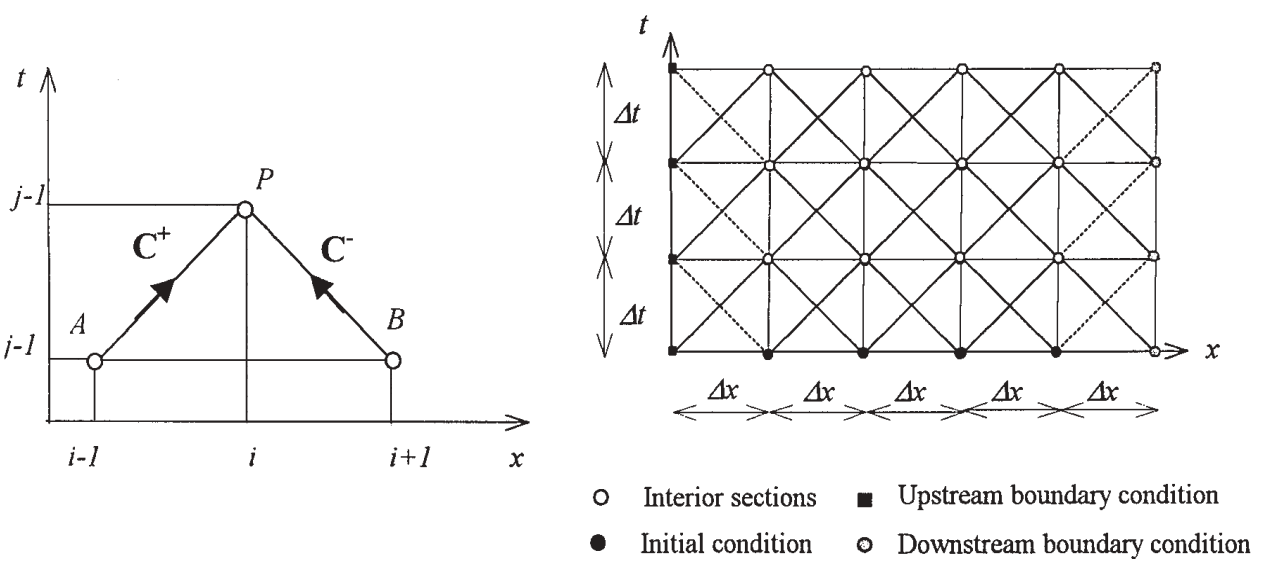

Figure 1 Method of characteristics—characteristic lines in plane $(x, t)$ (Chaudhry, 1987). 
which is equivalent to the following set of equations:

$$
\begin{aligned}
& C^{+}: h_{\mathrm{P}}+q_{\mathrm{P}}-c_{1}=0 \\
& C^{-}: h_{\mathrm{P}}-q_{\mathrm{P}}-c_{2}=0
\end{aligned}
$$

with

$$
\begin{aligned}
& c_{1}=h_{\mathrm{A}}+\left(1-\frac{\Delta h_{0}}{N}\left|\mathrm{q}_{\mathrm{A}}\right|\right) \mathrm{q}_{\mathrm{A}} \\
& c_{1}=h_{\mathrm{B}}-\left(1-\frac{\Delta h_{0}}{N}\left|\mathrm{q}_{\mathrm{B}}\right|\right) \mathrm{q}_{\mathrm{B}}
\end{aligned}
$$

or in an equivalent form:

$$
\begin{array}{llll}
h_{\mathrm{P}}=\frac{c_{1}+c_{2}}{2} & & h_{\mathrm{P}}=c_{1}-q_{\mathrm{P}} ; & q_{\mathrm{P}}=c_{1}-h_{\mathrm{P}} \\
q_{\mathrm{P}}=\frac{c_{1}-c_{2}}{2} & \text { or } & h_{\mathrm{P}}=c_{2}+q_{\mathrm{P}} ; & q_{\mathrm{P}}=h_{\mathrm{P}}-c_{2}
\end{array}
$$

and for the second order approximation of head losses, it yields:

$$
\begin{aligned}
& C^{+}: h_{\mathrm{P}}-h_{\mathrm{A}}+q_{\mathrm{P}}-q_{\mathrm{A}}+\frac{\Delta h_{0}}{\mathrm{~N}}\left|q_{\mathrm{P}}\right| q_{\mathrm{P}}=0 \\
& C^{-}: h_{\mathrm{P}}-h_{\mathrm{B}}-q_{\mathrm{P}}+q_{\mathrm{B}}-\frac{\Delta h_{0}}{N}\left|q_{\mathrm{P}}\right| q_{\mathrm{P}}=0
\end{aligned}
$$

which is equivalent to,

$$
\begin{aligned}
& h_{\mathrm{P}}=\frac{h_{\mathrm{A}}+h_{\mathrm{B}}+q_{\mathrm{A}}-q_{\mathrm{B}}}{2} \\
& q_{\mathrm{P}}=\frac{h_{\mathrm{A}}-h_{\mathrm{B}}+q_{\mathrm{A}}+q_{\mathrm{B}}}{1+\sqrt{1+2\left(\Delta h_{0} / N\right)\left|h_{\mathrm{A}}-h_{\mathrm{B}}+q_{\mathrm{A}}+q_{\mathrm{B}}\right|}}
\end{aligned}
$$

It is interesting to verify that, for second order approximation, the head, $h_{\mathrm{P}}$, is independent of the number of pipe sections (or pipe elements). This dimensionless form of pressurised transient flow equations has the advantage of being independent of the system characteristics.

\subsection{Energy dissipation}

Several formulations have been proposed to estimate the energy dissipation under unsteady conditions in turbulent regime. An extension of Brunone et al. (1991) formulation presented by Vitkovsky et al. (2000) has been analysed by Loureiro (2002) and Loureiro and Ramos (2003), showing a good agreement of energy dissipation for certain system characteristics. This formulation can be easily integrated into the MOC, avoiding the use of complex axi-simetric models. Generally, these types of formulations are composed of a first component calculated based on quasi-stationary hypothesis, $J_{\mathrm{qs}}$,

$$
J_{\mathrm{qs}}=\frac{f V^{2}}{2 g D}
$$

with $f=$ Darcy-Weisbach friction factor; $V=$ average velocity of the fluid in the cross-section of the pipe; and $D=$ inner pipe diameter; and other component which take account the unsteady effect, $J_{\mathrm{u}}$, as follows:

$$
J=J_{\mathrm{qs}}+J_{\mathrm{u}}
$$

According to Vitkovsky et al. (2000), the unsteady component can be estimated by the following equation:

$$
J_{\mathrm{u}}=\frac{k_{3}}{g A}\left(\frac{\partial Q}{\partial t}+c \operatorname{SGN}(Q)\left|\frac{\partial Q}{\partial x}\right|\right)
$$

which is based on Brunone et al. (1991) formula, being $k_{3}$ an empirical coefficient which depends on velocity profile, variation between steady and unsteady flow conditions, and $\operatorname{SGN}()$ the signal of the instantaneous mean velocity.

In this research work, a novel formulation based on Vitkovsky et al. (2000) formula with two new different empirical correctivecoefficients (Loureiro, 2002; Ramos and Loureiro, 2002) is presented and analysed:

$$
J_{\mathrm{u}}=\frac{1}{g A}\left(K_{v 1} \frac{\partial Q}{\partial t}+K_{v 2} c \operatorname{SGN}(Q)\left|\frac{\partial Q}{\partial x}\right|\right)
$$

This equation can be easily integrated into compatibility equations of MOC. The local and convective acceleration components can be solved according to the following numerical schemes (Covas, 2003) in order to avoid numerical instabilities:

\section{Local acceleration}

$$
\begin{aligned}
C^{+}: \frac{\partial Q}{\partial t}= & \theta \frac{Q_{i, j}-Q_{i, j-1}}{\Delta \mathrm{t}} \\
& +(1-\theta) \frac{Q_{i-1, j-1}-\mathrm{Q}_{i-1, j-2}}{\Delta t} \\
C^{-}: \frac{\partial Q}{\partial t}= & \theta \frac{Q_{i, j}-Q_{i, j-1}}{\Delta t} \\
& +(1-\theta) \frac{Q_{i+1, j-1}-Q_{i+1, j-2}}{\Delta t}
\end{aligned}
$$

with $\theta=$ convergence (or relax) coefficient (Ramos, 1986).

$$
\begin{aligned}
& \text { Convective acceleration } \\
& \qquad C^{+}: \frac{\partial Q}{\partial x}=\frac{Q_{i, j-1}-Q_{i-1, j-1}}{\Delta x} \\
& C^{-}: \frac{\partial Q}{\partial x}=\frac{Q_{i, j-1}-Q_{i+1, j-1}}{\Delta x}
\end{aligned}
$$

The term $\operatorname{SGN}(Q)$ takes into account the flow direction, which for the characteristic line $C^{+}$depends on the signal of $Q_{i-1, j-1}$ and for the $C^{-}$depends on the signal of $Q_{i+1, j-1}$. After the incorporation of the unsteady friction into the MOC, the characteristic lines are given by:

$$
\begin{aligned}
& C^{+}: Q_{i, j}=C_{\mathrm{P}}^{\prime \prime}-C_{\mathrm{a}}^{\prime} H_{i, j} \\
& C^{-}: Q_{i, j}=C_{N}^{\prime \prime}+C_{\mathrm{a}}^{\prime} H_{i, j}
\end{aligned}
$$

Whilst Covas (2003) used a second order implicit numerical scheme to calculate the coefficients $C_{\mathrm{P}}^{\prime \prime}, C_{N}^{\prime \prime}$ and $C_{\mathrm{a}}^{\prime}$ and one single decay coefficient $k_{3}$, Ramos and Loureiro (2002) and Loureiro and Ramos (2003) used a first order explicit scheme with two corrective coefficients, $K_{v 1}$ and $K_{v 2}$. The latter approach was followed herein as the use of two coefficients seemed to describe better the observed surge damping for plastic pipe materials (nonelastic behaviour which induce such greater damping and wave 
dispersion). Accordingly, coefficients $C_{\mathrm{P}}^{\prime \prime}, C_{\mathrm{N}}^{\prime \prime}$ and $C_{\mathrm{a}}^{\prime}$ are defined as follows:

$$
\begin{aligned}
C_{\mathrm{P}}= & Q_{i-1, j-1}+C_{\mathrm{a}} H_{i-1, j-1}-\mathrm{R} Q_{i-1, j-1}\left|Q_{i-1, j-1}\right| \\
C_{\mathrm{P}}^{\prime}= & C_{\mathrm{P}}+K_{v 1} \theta Q_{i, j-1}-K_{v 1}(1-\theta)\left(Q_{i-1, j-1}-Q_{i-1, j-2}\right) \\
& -K_{v 2} \operatorname{SGN}\left(Q_{i-1, j-1}\right)\left|Q_{i, j-1}-Q_{i-1, j-1}\right| \\
C_{\mathrm{P}}^{\prime \prime}= & \frac{C_{\mathrm{P}}^{\prime}}{1+K_{v 1} \theta} \\
C_{N}= & Q_{i+1, j-1}+C_{\mathrm{a}} H_{i+1, j-1}-\mathrm{R} Q_{i+1, j-1}\left|Q_{i+1, j-1}\right| \\
C_{N}^{\prime}= & C_{N}+K_{v 1} \theta Q_{i, j-1}-K_{v 1}(1-\theta)(20 \mathrm{~d}) \\
& -K_{v 2} \operatorname{SIGN}\left(Q_{i+1, j-1}-Q_{i+1, j-2}\right)\left|Q_{i, j-1}-Q_{i+1, j-1}\right| \\
C_{N}^{\prime \prime}= & \frac{C_{N}^{\prime}}{1+K_{v 1} \theta}
\end{aligned}
$$

with

$$
C_{\mathrm{a}}^{\prime}=\frac{C_{\mathrm{a}}}{1+K_{v 1} \theta} \quad \text { and } \quad C_{\mathrm{a}}=\frac{g A}{c}
$$

At the boundaries, additional equations must be specified.

\subsection{Surge damping curves}

A new simplified approach of the surge damping is presented taking into account the pressure peak damping in time. This damping can be a combined effect of the non-elastic behaviour of the pipewall, the steady and unsteady friction effect. This technique aims at the characterization of energy dissipation through the variation of the extreme piezometric head in time, in a simple and rapid implementation.

Generally the mechanical characteristics of pipe materials can be distinguished in three categories: (1) thermo-plastic behaviour, which includes HPPE and PVC pipes; (2) thermoelastic behaviour, which includes PRGF-Polyester reinforced with glass fibre, but only available for $D>400 \mathrm{~mm}$, conditioning the application in lab conditions; (3) elastic behaviour, which includes concrete, iron and steel pipes. From a practical point of view, there are no systems purely dissipative by friction effects or non-elastic effects, but systems with combined effects.

In the systems analysed in this current research, there are two types of pipe materials: (i) a less deformable material with quasielastic behaviour such as metal pipes and (ii) a more deformable materials with viscoelastic behaviour (i.e. plastic), such as HPPE and PVC. Specific formulations were developed and implemented in order to carry out the surge damping estimation for different pipe-wall characteristics.

In elastic pipe behaviour, the energy dissipation of the system in time for a rough turbulent flow, in a dimensionless form, varies with $h^{2}$ (or $q^{2}$, due to friction effects). Hence, the extreme values of head, $h=H /\left(\Delta H_{\mathrm{J}}\right)$, can be obtained according to the following equation

$$
h_{1}-h_{2}=K_{\text {elas }} \Delta h_{0} h^{2}
$$

where $h_{1}-h_{2}=$ dimensionless head difference between two successive peaks for different time calculation, $K_{\text {elas }}=$ damping factor, $\Delta h_{0}=$ friction effect and $\Delta H_{\mathrm{J}}=$ overhead of Joukowsky which is given by

$$
\Delta H_{\mathrm{J}}=\frac{c Q_{0}}{g A}
$$

The energy dissipation in time for this type of systems (i.e. low deformable pipe material or "rigid" pipes made of concrete or metal) can be evaluated by the following equation:

$$
\frac{\mathrm{d} h}{\mathrm{~d} \tau}=-K_{\text {elas }} \Delta h_{0} h^{2}
$$

assuming that $\tau=t /(2 L / c)$, and by integration, the time-head variation is given by

$$
h=\frac{1}{1 / h_{0}+K_{\text {elas }} \Delta h_{0}\left(\tau-\tau_{0}\right)}
$$

with $h_{0}=$ dimensionless head at $\tau_{0}=t_{0} /(2 L / c)$; and $t_{0}=$ time for the first pressure peak where the head is maximum.

According to the same type of analysis, in non-elastic pipe behaviour (e.g. plastic pipes), the pipe-wall retarded behaviour is the main factor for the pressure damping. Thus, in practical, the energy dissipation can be adequately reproduced by a proportionality to the head:

$$
h_{1}-h_{2}=K_{\text {plas }} \Delta h_{0} h
$$

and its time-variation can be evaluated by

$$
\frac{\mathrm{d} h}{\mathrm{~d} \tau}=-K_{\text {plas }} \Delta h_{0} h
$$

which by integration is equivalent to

$$
h=h_{0} \mathrm{e}^{-K_{\text {plas }} \Delta h_{0}\left(\tau-\tau_{0}\right)}
$$

This equation is in accordance with Pearsall (1965) and with the typical behaviour of a viscoelastic pipe (Gally et al., 1979; Ghilardi and Paoletti, 1986; Covas et al., 2002a).

For systems with combined effects (i.e. elastic and plastic response), the surge damping can be evaluated by a combination of both effects as follow:

$$
h_{1}-h_{2}=K_{\text {plas }} \Delta h_{0} h+K_{\text {elas }} \Delta h_{0} h^{2}
$$

that, in time-variation, is equivalent to

$$
\frac{\mathrm{d} h}{\mathrm{~d} \tau}=-K_{\text {plas }} \Delta h_{0} h-K_{\text {elas }} \Delta h_{0} h^{2}
$$

and after the integration yields in this final form,

$$
h=\frac{1}{\left(K_{\text {elas }} / K_{\text {plas }}+1 / h_{0}\right) \mathrm{e}^{K_{\text {plas }} \Delta h_{0}\left(\tau-\tau_{0}\right)}-\left(K_{\text {elas }} / K_{\text {plas }}\right)}
$$

where $K_{\text {plas }}$ and $K_{\text {elas }}$ are damping coefficients to take account the plastic and elastic effects, respectively.

\section{Analysis of results}

\subsection{Classic waterhammer theory}

First of all, a theoretical analysis applied to a simple elastic pipe system with a reservoir at upstream and a valve at downstream is discussed in order to better identify the physical phenomena associated with pressure head variation, both with instantaneous closure manoeuvre (i) without head losses, $\Delta h=0$, and (ii) with 


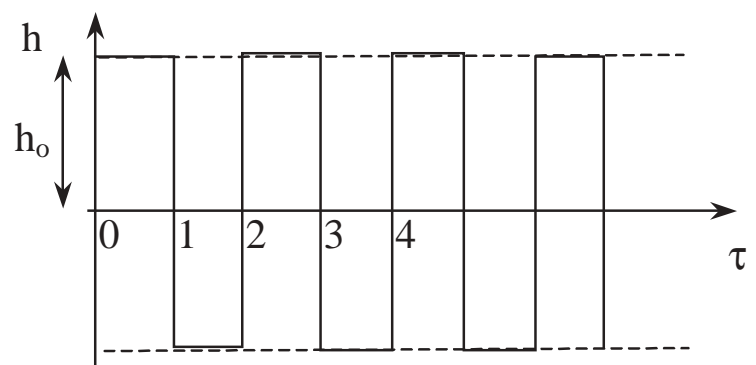

Figure 2 Typical elastic pipe-wall behaviour for instantaneous valve closure and no head losses.

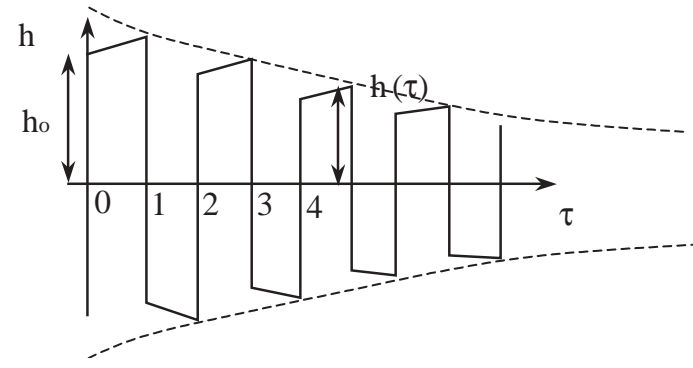

Figure 3 Typical elastic pipe-wall behaviour for instantaneous valve closure and with head losses.

head losses along the pipe flow, $\Delta h \neq 0$ :

(i) Instantaneous valve closure without head losses $(\Delta h=0)$ Fig. 2. Based on Eq. (24), the extreme dimensionless head values can be evaluated by considering $\Delta h_{0}=\Delta H_{0} / \Delta H_{\mathrm{J}}$ that, in this case, is equal to $0 ; h=H / \Delta H_{\mathrm{J}} ; h_{0}=$ $H_{0} / \Delta H_{\mathrm{J}}=1$, since $H_{0}=\Delta H_{\mathrm{J}} ; \tau=t /(2 L / c)$, that results $h=h_{0}$ for extreme positive values, without any type of damping.

(ii) Instantaneous valve closure with head losses $\left(\Delta h_{0} \neq 0\right)$ Fig. 3. According to Eq. (24), the extreme dimensionless head values along time steps (i.e. when $\tau \rightarrow \infty$ ) tend to be 0 (i.e. $h \rightarrow 0$ ). This means, contrary to case (i), that there is a complete attenuation of the head variation in time at the valve section, as shown in the damping tendency presented in Fig. 3.

Based on several types of simulations, for different values of discharge, $Q$, and valve closure time for fast manoeuvres, $T c \leq 2 L / c$, a pure elastic model based on Eq. (24) fits quite well to the classic waterhammer model results (Fig. 4), commonly used for design purposes. This analysis allows the identification of the damping capacity of commercial software packages that generally describe quite accurately the waterhammer in low deformable pipe systems (e.g. metal pipes), which have a predominant elastic behaviour.

\subsection{Experimental procedures}

\subsubsection{Unsteady friction (UF) estimation}

The use of different weight coefficients $\left(K_{v 1}\right.$ and $\left.K_{v 2}\right)$, applied to the convective and the local acceleration terms in Eq. (17), to estimate the unsteady friction significantly improves the agreement between numerical results and experimental observations comparatively to a unique coefficient used by Brunone et al. (1995) and, after, modified by Vitkovsky et al. (2000) (Loureiro, 2002; Ramos and Loureiro, 2002; Loureiro and Ramos, 2003). With this novel approach, it is possible to reproduce reasonably well the experimental observations in terms of pressure damping and phase (Fig. 5). However, the shape of this pressure wave propagation is much sharper than the real one. For long pipelines with high steady state flows, where the packing effect is very important, the results fit quite well the pressure peaks at the valve section.

The coefficients $K_{v 1}$ and $K_{v 2}$ have been estimated based on the fitting of the results of numerical simulations with experimental data, for different initial steady state conditions (Loureiro, 2002). This analysis has shown that these parameters are practically constant for different Reynold numbers, defining the limits for $K_{v}$ variation of the formula proposed by Vardy and Brown (1995, 1996):

$$
K_{v}=2 \sqrt{\frac{7.41}{\operatorname{Re}^{\log \left(14.3 / \mathrm{Re}^{0.05}\right)}}}
$$

Several tests have been carried out in a lab facility System 1 (S1), characterised by an HPPE (high performance polyethylene) pipe with the length $L_{1}=100 \mathrm{~m}$ or $L_{2}=200 \mathrm{~m}$, an internal diameter $\mathrm{Di}=0.044 \mathrm{~m}$ and a wave speed $c=280 \mathrm{~m} / \mathrm{s}$. For this system, it has been verified numerically that the term $K_{v 1} \partial Q / \partial t$ affects the phase shift of transient pressure waves and $K_{v 2} \partial Q / \partial x$ the damping effect. The numerical pressure wave propagates faster than the experimental wave for small values of $K_{v 1}$ and tends to be slightly delayed than the observed wave for higher values of $K_{v 1}$. For the experimental procedure of system $\mathrm{S} 1, K_{v 1}$ varied between $[0.004 ; 0.0054]$ and $K_{v 2}$ between $[0.033 ; 0.05]$, inversely to water column inertia ( $L=100 ; 200 \mathrm{~m})$ (Fig. 6a). Figure 6(b) shows that the coefficient $K_{v 2}$ is much more dependent on the pipeline head losses than $K_{v 1}$, as it attains higher values for smaller head losses.

Although Eq. (17) allows a good fitting between numerical results and experimental tests in terms of pressure damping and phase shift, there are still some differences, particularly, regarding the actual shape of the transient pressure wave. Covas et al. (2002a,b) analysed, both theoretically and experimentally, waterhammer in a polyethylene pipe. These authors have observed that the shape, the amplitude and the dispersion of the transient pressure wave are mainly caused by the viscoelastic behaviour of the polyethylene pipe material, rather than by the frictional shear stress in the pipe-wall.

\subsubsection{Damping effect (DE) analysis}

Different case studies Experimental tests have been performed, in order to analyse the dynamic response of single pipes with different characteristics: pipe materials, diameters, pipe lengths and thickness and operating conditions. The following five types of facilities have been analysed (Table 1):

System 1 (S1) - an HPPE (high performance polyethylene) pipe with the length $L_{1}=100 \mathrm{~m}$ or $L_{2}=200 \mathrm{~m}$, an internal diameter $\mathrm{Di}=0.044 \mathrm{~m}$ and a wave speed $c=280 \mathrm{~m} / \mathrm{s}$; 

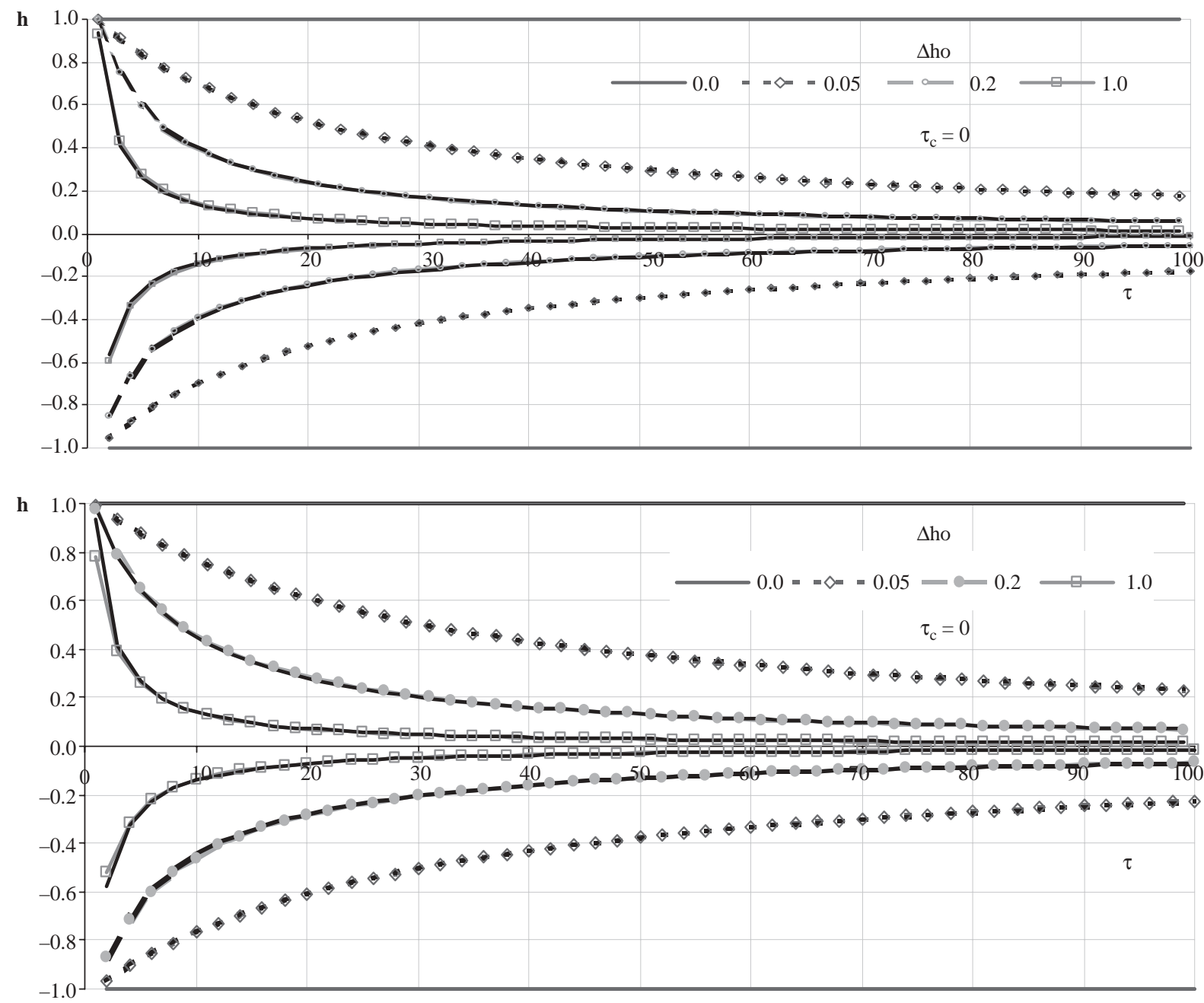

Figure 4 Typical elastic behaviour. Agreement between classic waterhammer simulation and Eq. (24) for different $\tau c$ and discharge values.
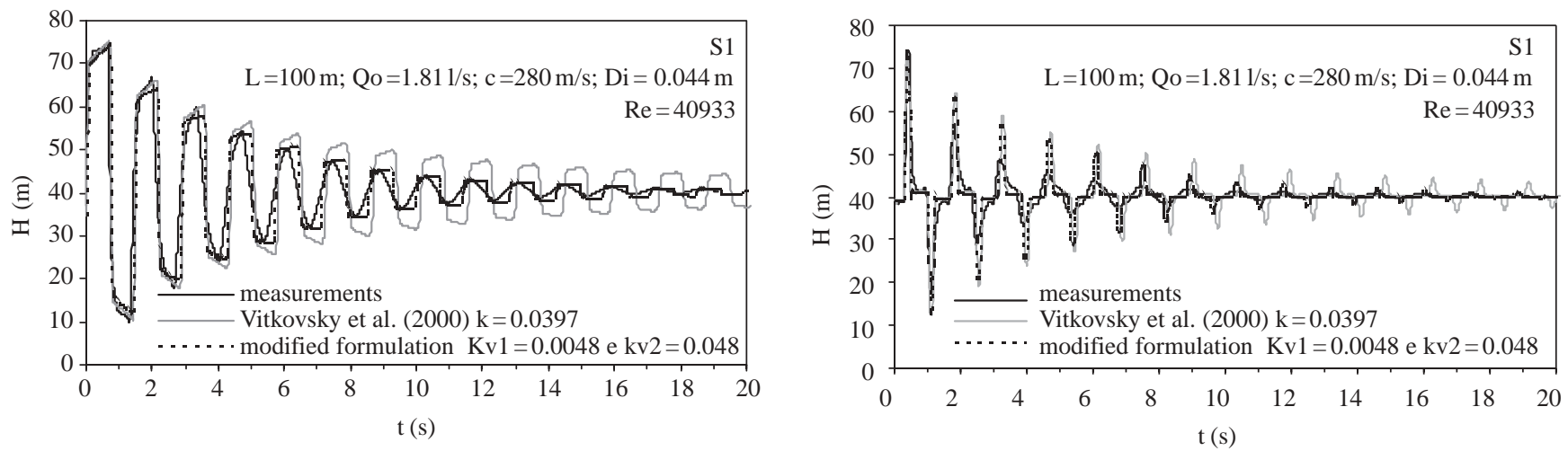

Figure 5 Comparison of piezometric heads: experimental measurements, Vitkovsky et al. (2000) and modified formulation-Eq. (17) at the valve section and at the middle of the pipe.

System 2 (S2) —an HPPE pipe with the length $L=250 \mathrm{~m}$, an internal diameter $\mathrm{Di}=0.050 \mathrm{~m}$ and a wave speed $c=330 \mathrm{~m} / \mathrm{s}$; System 3 (S3) - a PVC pipe with a length $L 1=14 \mathrm{~m}$ or $L 2=$ $28 \mathrm{~m}$, an internal diameter $\mathrm{Di}=0.045 \mathrm{~m}$ and a wave speed $c=400 \mathrm{~m} / \mathrm{s}$;

System 4 (S4) — (based on Doc8664-51-Benchmark Analysis) a steel pipe with a length $L=3000 \mathrm{~m}$, an internal diameter $\mathrm{Di}=$ $0.400 \mathrm{~m}$ and a wave speed $c=1000 \mathrm{~m} / \mathrm{s}$;

System 5 (S5)—(based on Pezzinga and Scandura, 1995) a zinc plated steel with a length of $L_{1}=78 \mathrm{~m}$ and $L_{2}=144 \mathrm{~m}$, an internal diameter $\mathrm{Di}=0.053 \mathrm{~m}$ and a wave speed $c=$ $1386 \mathrm{~m} / \mathrm{s}$

Cases studies S1, S2 and S3 are obtained by the authors in laboratory system composed by an air-vessel at upstream to keep the pressure constant and at downstream end there are two ball valves, one to discharge control and another to originate the manoeuvre, respectively, discharging to the atmosphere. Systems S4 and S5 are case tests available in the literature. 


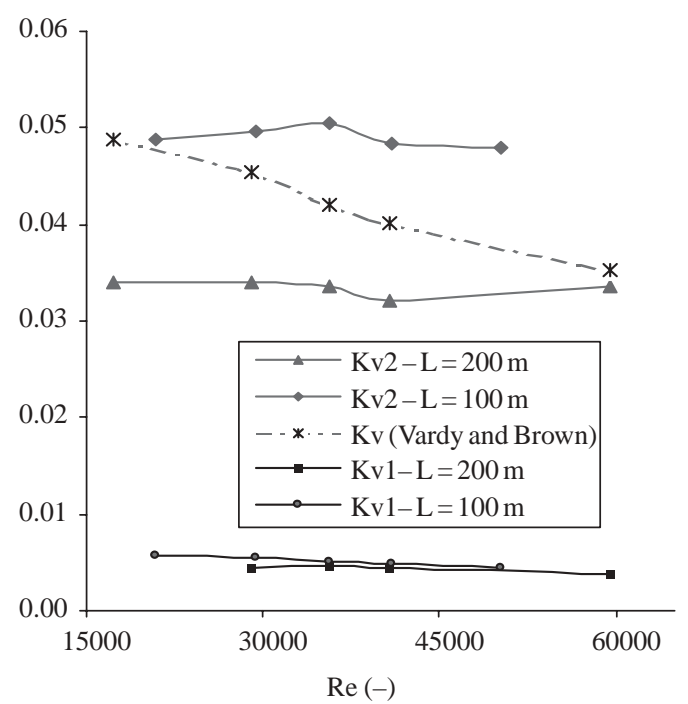

(a)
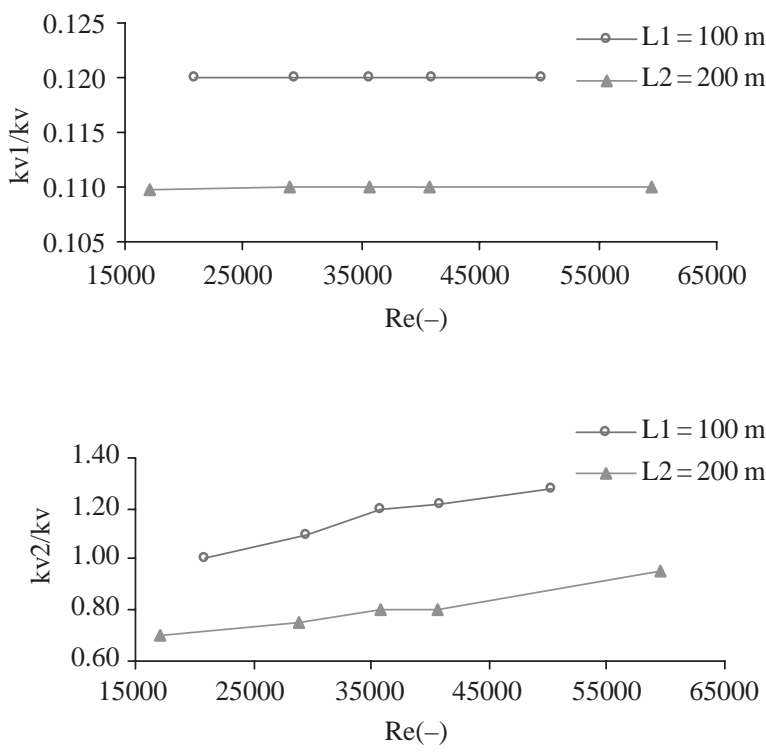

(b)

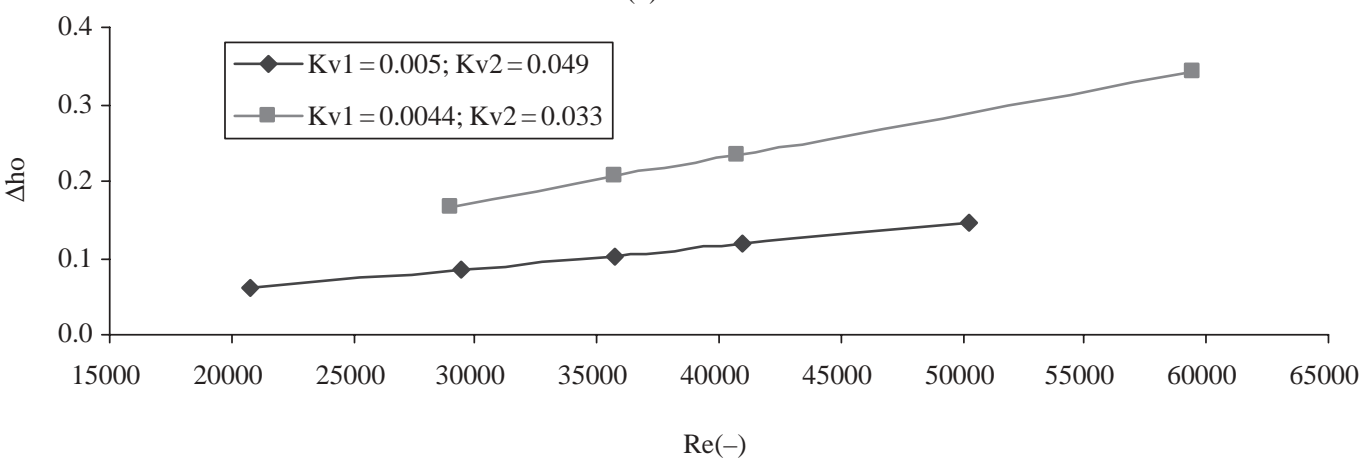

Figure 6 Values of $K_{v 1}$ and $K_{v 2}$ for different values of Reynolds number (a) and relative head losses (b).

Table 1 Parameters estimation for damping effect in different system characteristics

\begin{tabular}{|c|c|c|c|c|c|c|c|c|}
\hline \multirow{2}{*}{$\begin{array}{l}\text { System } \\
\text { type-pipe } \\
\text { material }\end{array}$} & \multicolumn{8}{|c|}{ System characteristics } \\
\hline & $\begin{array}{c}L \\
(\mathrm{~m}) \\
(1)\end{array}$ & $\begin{array}{l}\mathrm{Di} \\
(\mathrm{m}) \\
(2)\end{array}$ & $\begin{array}{c}Q \\
(1 / \mathrm{s}) \\
(3)\end{array}$ & $\begin{array}{c}c \\
\left(\mathrm{~ms}^{-1}\right)\end{array}$ & $\begin{array}{l}\text { hf } \\
(-) \\
(5)\end{array}$ & $\begin{array}{l}k_{1} \\
(-) \\
(6)\end{array}$ & $\begin{array}{c}k_{2}(32) \\
(-) \\
(7)\end{array}$ & $\begin{array}{c}k_{2}(33) \\
(-) \\
(8)\end{array}$ \\
\hline \multirow[t]{6}{*}{$\overline{\mathrm{S} 1-\mathrm{HPPE}}$} & 100 & 0.044 & 0.87 & 280 & 2.48 & 1.02 & - & 0.14 \\
\hline & & & 1.48 & & 1.46 & & & 0.16 \\
\hline & & & 2.40 & & 0.90 & & & 0.17 \\
\hline & 200 & & 0.80 & & 2.69 & & & 0.26 \\
\hline & & & 1.90 & & 1.13 & & & 0.27 \\
\hline & & & 2.75 & & 0.78 & & & 0.29 \\
\hline \multirow[t]{4}{*}{ S2-HPPE } & 250 & 0.050 & 1.10 & 330 & 2.38 & 0.99 & - & 0.23 \\
\hline & & & 1.50 & & 1.75 & & & 0.26 \\
\hline & & & 2.00 & & 1.31 & & & 0.27 \\
\hline & & & 2.60 & & 1.01 & & & 0.30 \\
\hline \multirow[t]{3}{*}{ S3-PVC } & 14 & 0.045 & 1.50 & 400 & 0.77 & 1.02 & - & 0.06 \\
\hline & 28 & & 1.00 & & 1.20 & & & 0.04 \\
\hline & & & 1.15 & & 1.08 & & & 0.05 \\
\hline \multirow[t]{2}{*}{ S4-steel } & 3000 & 0.400 & 57.00 & 1000 & 7.06 & 0.98 & 0.24 & - \\
\hline & & & 98.00 & & 4.11 & & 0.30 & \\
\hline \multirow[t]{3}{*}{ S5-zinc plated steel } & 78 & 0.053 & 0.40 & 1386 & 1.79 & 1.01 & 0.03 & 0.02 \\
\hline & & & 0.60 & & 1.20 & & 0.03 & 0.02 \\
\hline & 144 & & 0.40 & & 1.33 & & 0.03 & 0.03 \\
\hline
\end{tabular}


Benchmark analysis Considering Eqs (24) and (27), after adequate algebraic transformations based on the final steady state piezometric head $H_{\mathrm{f}}$, normally associated to each system characteristics, or in dimensionless form $h_{\mathrm{f}}=H_{\mathrm{f}} / \Delta H_{\mathrm{J}}$, which allow to better understand the actual head variation, $h=H / \Delta H_{\mathrm{J}}$. The estimative of the extreme pressure heads during fast changes of flow conditions must include the following terms: (1) the final steady state piezometric head, $h_{\mathrm{f}}$, for which the pressure fluctuations tend and for a completely closure, it is equivalent to the upstream static head; (2) instantaneous overpressure given by Joukowsky formula, $K_{1} Q_{0}$, or in dimensionless form $k_{1} \approx 1$ (being $k_{1}=K_{1} Q_{0} / \Delta H_{\mathrm{J}}$ ); 3) damping effect, $K_{2} t$, or in dimensionless form $k_{2} \tau$, which depends on total head losses, among other factors (pipe-wall behaviour), that is expressed by an inverse term for elastic behaviour and by an exponential equation for plastic type response. Accordingly, Eqs (24) and (27) can be replaced by Eqs (32) and (33), after adequate transformations based on the tendency to the final steady state piezometric head line, as follows:

Elastic behaviour (i.e. low deformable pipes):

$$
\begin{aligned}
& H=H_{\mathrm{f}} \pm \frac{K_{1} Q_{0}}{\left(1+K_{2} t\right)} \\
& \text { in dimensionless form: } h=h_{\mathrm{f}} \pm \frac{k_{1}}{\left(1+k_{2} \tau\right)}
\end{aligned}
$$

Plastic behaviour (i.e. viscoelastic materials):

$$
\begin{aligned}
& H=H_{\mathrm{f}} \pm K_{1} Q_{0} \mathrm{e}^{-K_{2} t} \\
& \text { in dimensionless form: } h=h_{\mathrm{f}} \pm k_{1} \mathrm{e}^{-k_{2} \tau}
\end{aligned}
$$

being the sign \pm for up-surge and down-surge, respectively.

This analysis was carried out for different system characteristics and for different pipe lengths. For systems S1, S2 and S3 composed of plastic pipes (i.e. HPPE and PVC), Eq. (33) fits well the observed surge damping (Figs 7-9; Table 1). In case of systems S4 and S5, with an elastic mechanical behaviour as the main characteristic of metal materials, Eq. (32) is much more adequate (Figs 10 and 11; Table 1). According to Table 1 for both pipe-wall cases, i.e. plastic and metal pipes, $k_{2}$ has different values and it is directly proportional to discharge values but inversely to the head losses associated to each pipe length.

Figure 7 shows the most rapid surge damping in the system with smaller length. Maximum and minimum pressure values, attained in the first peaks are almost the same for both length and flow conditions. The packing effect, most notorious in the longer circuit, practically is compensated by the steady state head losses.

Figure 8 presents the surge damping in a longer pipeline (system S2), with a higher diameter and thickness than system S1, but with equivalent response. As for the former case, the plastic behaviour obtained by Eq. (33) fits quite well.

In system S3, the damping effect is higher as the discharge and the smaller is the length (Fig. 9). Definitely, classic waterhammer models, which follow the elastic type response given by Eq. (32), do not have the capacity to reproduce the real damping induced by plastic pipe materials.
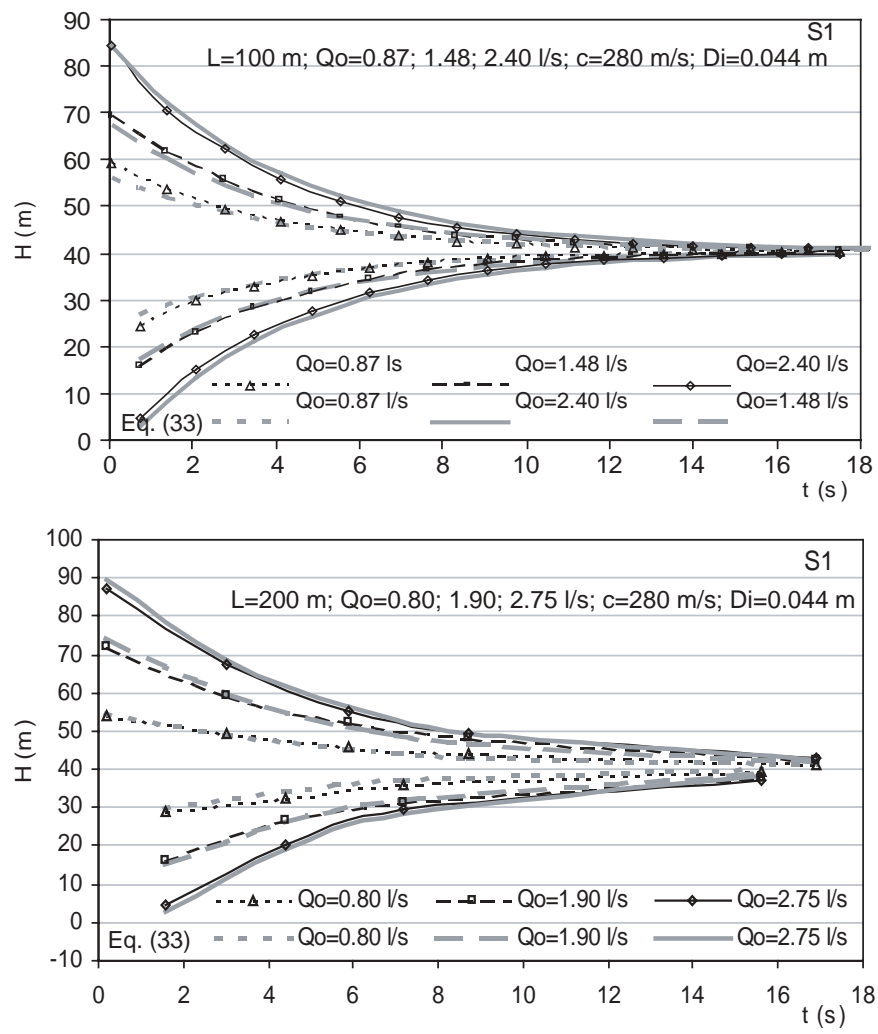

Figure 7 Surge damping of system S1 for different discharge and pipe length.

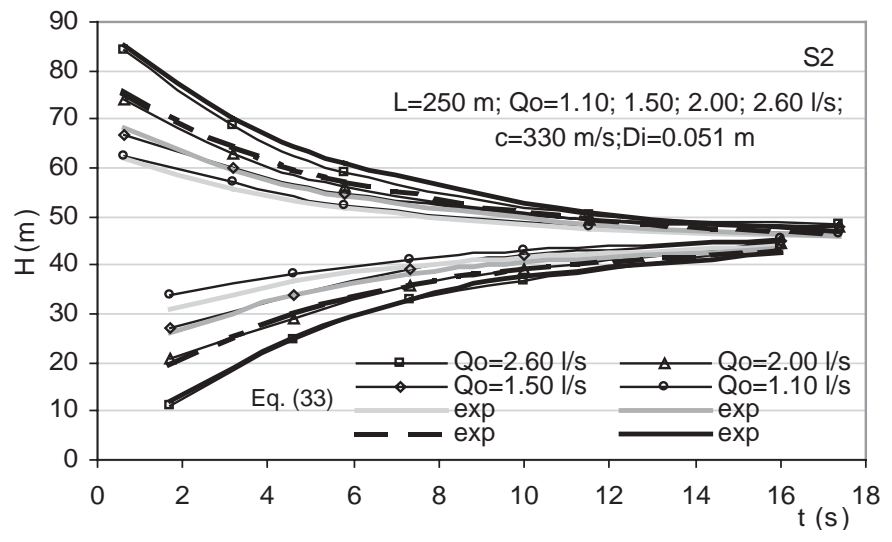

Figure 8 Surge damping of system S2 for different discharge values.

However, for metal pipes, the behaviour is much more similar to the classic waterhammer models, which are based on a linear elastic rheological behaviour of the pipe-wall (Figs 10 and 11), which the elastic formulation, Eq. (32) describes reasonably well this behaviour. Since in system S5 (Fig. 11) the effect of friction is smaller due to low discharge values, a good agreement for both formulations is obtained.

System S2 was chosen to analyse the fitting in detail due to its higher thickness, when compared to system S1. Analysis of combined effects of elastic and non-elastic type was developed by using Eq. (30) and presented in Fig. 12. The zero value for $K_{2 \text { plas }}$ or $K_{\text {2elas }}$ indicates which effect (i.e. plasticity or elasticity) can be negligible. For this system, it was observed the behaviour is highly conditioned by a plastic type response (i.e. $K_{2 \text { plas }}=0.14$ when compared with $K_{\text {2elas }}=0.07$ ), as expected. Figure 12 

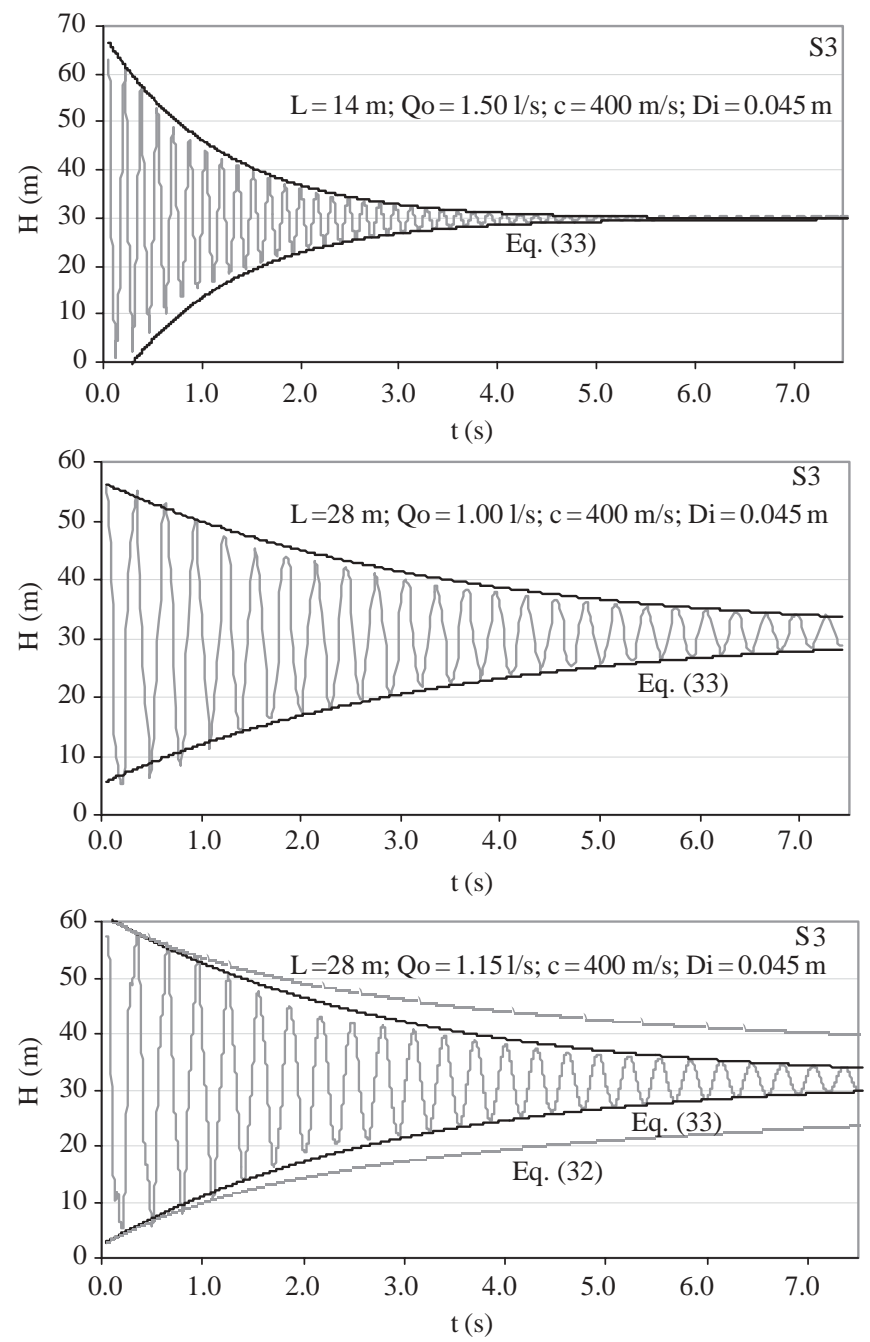

Figure 9 Sensitivity analysis to damping effect of S3, for different system characteristics.

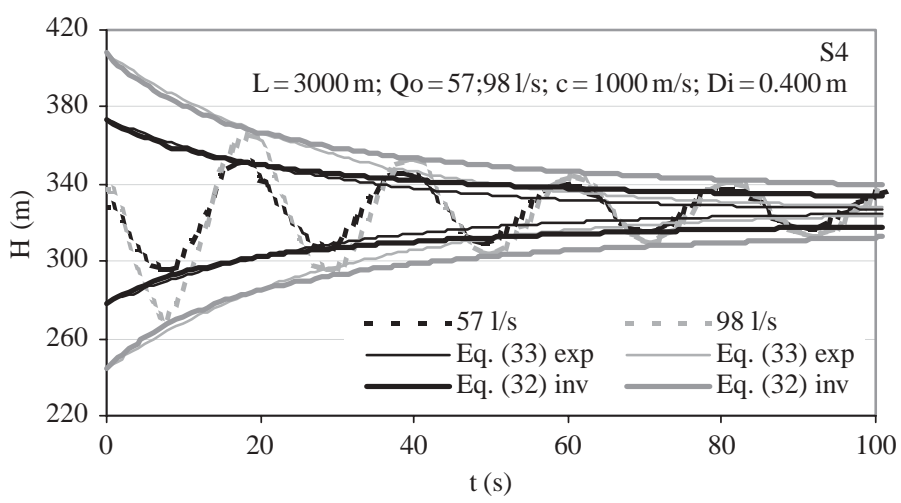

Figure 10 Selection of the best fit for pressure surge for different discharge values of system S4.

shows as well a good fitting for all type of formulations only for the first time steps, although the viscoelastic damping effect is most notorious along time pressure wave propagation. A classic formulation of waterhammer (i.e. with $K_{2 p l a s}=0$ ) cannot reproduce in this system the correct damping effect in the time of simulation.
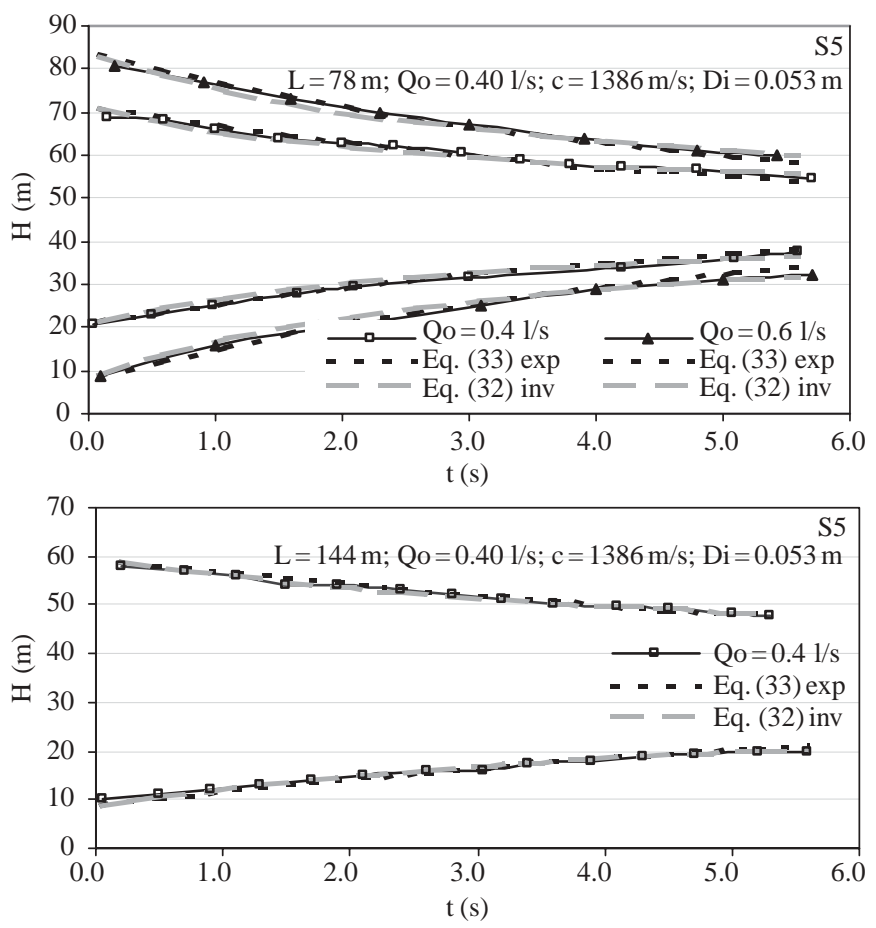

Figure 11 Damping analysis for both approaches and for system S5. Best fitting obtained with Eq. (32).

\subsubsection{Link between $U F$ and $D E$}

Since system $\mathrm{S} 1$ is composed of a plastic pipe response and it cannot be accurately simulated by the classic waterhammer formulation, it was compared with both approaches presented herein (i.e. unsteady friction (UF) and damping effects (DE) estimations). These both approaches have different formulations not associated, although they have an equivalent response type for the estimation of surge damping, which is analysed in detail. After identifying that only both terms $K_{v 2}$ from Eq. (17) and K2 from Eq. (33) can be related since they reproduce the pressure wave attenuation effects, in Fig. 13, it was observed a constant ratio between these parameters (i.e. $K_{v 2} / K 2 \approx 0.19$ ), for different discharge values, independently of the system configuration (i.e. with $L=100 \mathrm{~m}$ - diamond marker or $L=200 \mathrm{~m}$ - triangle marker). In Fig. 13 , the parameter $\Delta H_{0} / L$ represents the total head losses for each pipe length, which is also associated to the surge damping. This constant ratio means there is a surge damping effect, which is dependent on the system characteristics.

\section{Conclusions}

According with this analysis, the following remarks can be made:

- Generally, all formulations allow the estimation of the maximum overpressure after a fast manoeuvre. However, the differences increase with the simulation time, depending on the capability of the transient model to describe the most important parameters of the system.

- Equation (16) provides a good approximate solution for unsteady friction effect; however, it is not enough to reproduce 

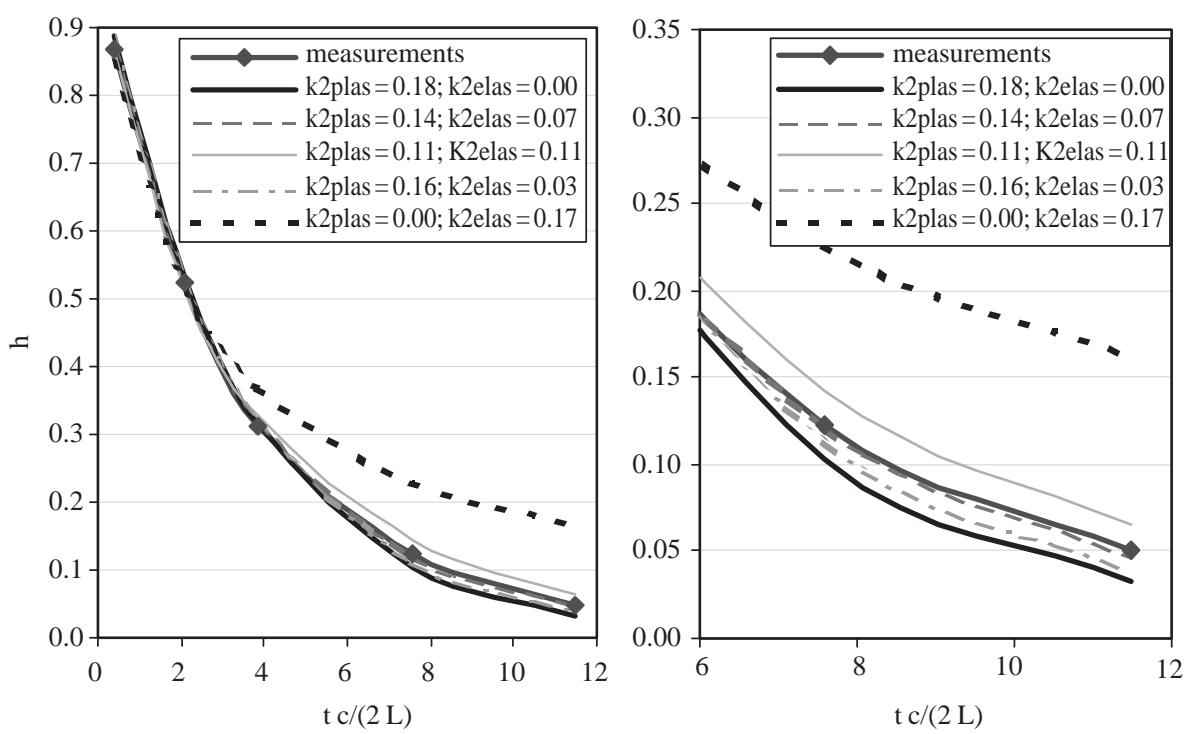

Figure 12 Sensitivity analysis to plastic and elastic response effects when applied to system S2.

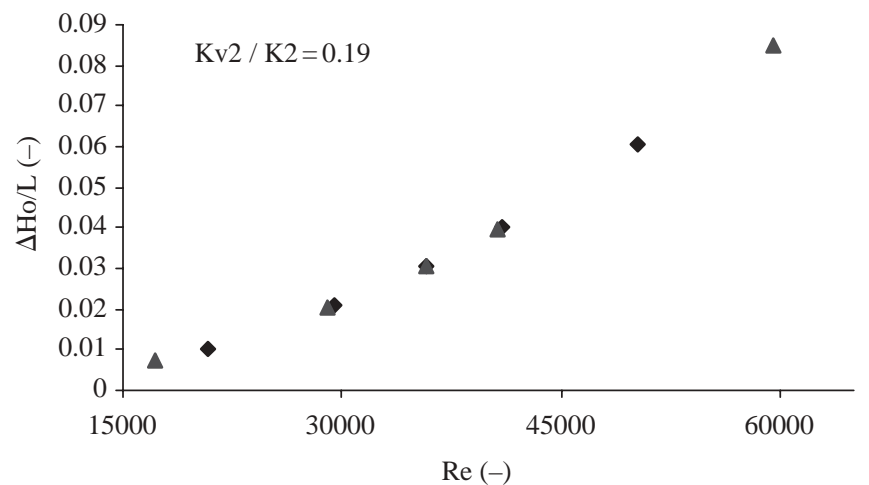

Figure 13 Constant correlation between damping coefficients of both approaches, for different Reynolds and head losses in the system S1.

accurately some particular experimental tests, specially, in plastic pipe systems.

- Two different corrective coefficients $\left(K_{v 1}\right.$ and $\left.K_{v 2}\right)$ associated to the local and convective acceleration in the unsteady friction formulation, Eq. (17), have been analysed. It was shown the use of these two coefficients, instead of a single one, improves the fitting between the results of the numerical simulations and the experimental measurements. The term $K_{v 1}$ (i.e. the wave phase coefficient), which affects the local acceleration, is responsible for the wave phase and the term $K_{v 2}$ (i.e. damping effect coefficient), which affects the convective acceleration, influences the surge damping, being always, for the analysed system, $K_{v 1}<K_{v 2}$ (i.e. $K_{v 1} \approx 10 \% K_{v 2}$ ).

- Classic waterhammer models only describe the elastic effects (using the quasi-stationary condition for friction losses estimation), being only reasonably adequate to simulate systems with elastic behaviour (i.e. low deformable pipe-walls - metal or concrete).

- Being the plastic pipe with a future increasing application, the viscoelastic effect must be considered, either for model calibration, leakage detection or in the prediction of operational conditions (e.g. start-up or trip-off electromechanical equipment, valve closure or opening).
- Aiming at the operational system response, the damping effect can be estimated by Eqs (32) or (33), depending on the main system characteristics (i.e. elastic or plastic type response), being $K_{1}$ related to the Joukowsky overpressure (or $k_{1} \approx 1$ ) and $K_{2} t$ (or $k_{2} \tau$ ) the attenuation factor between two successive wave pressure peaks, which depends on the pipe length, type of pipe material, pipe roughness or inertial effects (i.e. $\mathrm{d} Q / \mathrm{d} t$ ). Alternatively other equivalent dimensionless formulations can be applied by using Eqs (24), (27) or (30) for elastic, nonelastic or combined effects, respectively;

- The coefficient $K_{2}$ depends on each system characteristics (i.e. inverse formulation for low deformable pipe materialsEq. (32), or exponential formulation for high deformable pipe materials-Eq. (33)). In the inverse formulation, $K_{2}$ represents the energy dissipation only due to friction effect, which for water and turbulent flow can be represented as a function of $Q^{2}$. In the exponential formulation, $K_{2}$ is considered proportional to $Q$, which includes energy dissipation due to the lack of elasticity of the system (e.g. fluid, pipe walls, eventual presence of air pockets) and the effect of inertia effects (i.e. $\mathrm{d} Q / \mathrm{d} t)$.

Plastic pipes or systems with dissolved air (Pearsall, 1965; Covas et al., 2003), have the predominance of non-elastic effects. On the contrary, metal and concrete pipes, with rough material and without air mixing, have a typical elastic behaviour.

In practice, the estimation of coefficient $K_{2}$ (or $k_{2}$ in dimensionless form) can be a difficult task, as this coefficient depends on several factors, such as inertial effects (associated with the pipe length), pipe materials, pipe roughness and inertial forces $(\mathrm{d} Q / \mathrm{d} t)$.

\section{Acknowledgments}

The authors wish to express thanks to SMT4-CT97 2188 EU project (Transient Pressures in Pressurised Conduits for Municipal Water and Sewage Water Transport) for the use of the data of system S4, as well as to LHRH of DEC/IST for data 
collection of transient events and FCT by the financial support to the project POCTI/37798/ECM/2001.

\section{Notation}

$A=$ cross-section flow area

$c=$ wave speed

$\mathrm{Di}=$ internal diameter of the pipe

$E=$ Young's modulus of elasticity of the conduit walls

$g=$ gravitational acceleration

$h=$ relative head $\left(h=H / \Delta H_{\mathrm{J}}\right)$

$H=$ piezometric head

$J=$ hydraulic gradient

$J_{q s}=$ hydraulic gradient due to steady-state conditions

$J_{u}=$ hydraulic gradient due to unsteady conditions

$K=$ the bulk modulus of elasticity

$K_{1}=$ overpressure coefficient from Joukowsky formula $\left(K_{1}=c /(g S)\right)$ for damping curves

$K_{2}=$ damping coefficient for damping curves

$K_{\text {2elas }}=$ damping coefficient for elastic effect

$K_{2 \text { plas }}=$ damping coefficient for plastic effect

$k_{3}=$ decay coefficient (Brunone et al., 1991)

$K_{v 1}=$ wave phase coefficient for unsteady friction

$K_{v 2}=$ damping effect coefficient for unsteady friction

$L=$ pipe length

$N=$ number of pipe elements

$q=$ relative discharge

$Q, Q_{0}=$ discharge flow; discharge of the steady-state condition

$S=$ flow cross-section

$t=$ time

$V=$ fluid velocity

$x=$ distance along the pipe axis

$\Delta H_{0}=$ total head losses

$\Delta H_{\mathrm{J}}=$ Joukowsky overpressure $\left(\Delta H_{\mathrm{J}}=c Q /(g S)=K_{1} Q\right)$

$\Delta h_{0}=$ relative head losses $\left(\Delta h_{0}=\Delta H_{0} / \Delta H_{\mathrm{J}}\right)$

$\rho=$ fluid density

$\psi=$ parameter that depends on the elastic properties of the conduit

$\tau=$ relative time $(\tau=t /(2 L / c))$

\section{References}

1. Abreu, J.M. and AlmeidA, A.B. (2000). "Pressure Transient Dissipative Effects: A Contribution for Their Computational Prediction". Proceedings of the 8th International Conference on Pressure Surges, BHR Group Ltd, 12-14 April, The Netherlands, pp. 499-517.

2. Almeida, A.B. and Koelle, E. (1992). Fluid Transients in Pipe Networks. C. M. P., Elsevier Applied Science, Amsterdam.

3. Axworthy, D.H., Ghidaoui, M.S. and McInnis, D.A. (2000). "Extended Thermodynamics Derivation of Energy Dissipation in Unsteady Pipe Flow". J. Hydraul. Engng. ASCE 126, 276-287.
4. Bergant, A., Simpson, A.R. and Vitkovsky, J. (2001). "Developments in Unsteady Pipe Flow Friction Modeling", J. Hydraul. Res. IAHR 39, 239-247.

5. BorgA, A. (1986). "Mathematic Modeling of Macrocavitation in Pump Systems". MSc Thesis, Technical University of Lisbon-IST, Portugal (in Portuguese).

6. Bratland, O. (1986). "Frequency-dependent Friction and Radial Kinetic Energy Variation in Transient Pipe Flows". Proceedings of the 5th International Conference on Pressure Surges, BHRA, Hanover, Germany, D2, pp. 95-101.

7. Brunone, B., Golia, U.M. and Greco, M. (1991). "Modelling of Fast Transients by Numerical Methods". Proceedings of the International Conference on Hydraulic Transients with Water Column Separation (9th and Last Round Table of IAHR Group), June, Valencia, Spain, pp. 273-281.

8. Brunone, B., Golia, U.M. and Greco, M. (1995). "Effects of Two-dimensionality on Pipe Transients Modelling". J. Hydraul. Engng. ASCE 121(12), 906-912.

9. Chaudhry, M.H. (1987). Applied Hydraulic Transients, 2nd edn. Van Nostrand Reinhold Company, New York.

10. Covas, D. (2003). Inverse Transient Analysis for Leak Detection and Calibration of Water Pipe Systems. Modelling Special Dynamic Effects. Department of Civil and Environmental Engineering, Imperial College of Science, Technology and Medicine, London, UK.

11. Covas, D. and Ramos, H. (1999). "Leakage Detection in Single Pipelines Using Pressure Wave Behaviour". Proceedings of CCWI'99, Exeter, UK.

12. Covas, D. and Ramos, H. (2001). "Hydraulic Transients Used for Leakage Detection in Water Distribution Systems". Proceedings of the 4th International Conference on Water Pipeline Systems, BHR Group, 28-30 March, York, UK, pp. 227-241.

13. Covas, D., Stoianov, I., Maksimović, C., Graham, N., RAmos, H. and ButLer, D. (2001). "Leakage Detection in Pipe Systems by Inverse Transient Analysis". Proceedings of WSS, Vol. 2, Leicester, UK, pp. 3-16.

14. Covas, D., Stoianov, I., Maksimović, C., Graham, N., RAmos, H. and Butler, D. (2002a). "Waterhammer in PE Pipes: Conceptual Model \& Exp. Analysis". Urban Water (submitted and accepted in 2002).

15. Covas, D., Stoianov, I., Maksimović, C., Graham, N., Ramos, H. and Butler, D. (2002b). "Hydraulic Transients in Polyethylene Pipes”. EWRSA, ASCE, 19-22 May, Virginia-EWRI, Roanoke.

16. Covas, D., Stoianov, I., Graham, N., Maksimović, C., RAmos, H. and Butler, D. (2002c). "Inverse Transient Analysis for Leak Detection and Calibration-A Case Study in a Polyethylene Pipeline". Proceedings of Hydroinformatics 2002, 1-5 July, Cardiff, Wales, UK.

17. Covas, D., Ramos, H., Stoianov, I., Graham, N. and MAKsimovic, C. (2003). "Dissipation of Pressure Surges in Water Pipeline Systems, Pumps, Electomechanical Devices and Systems. In: CABrera, E. and CABrera E. JR (eds), 
PEDS Applied to Urban Water Management, Valencia, Spain.

18. DOC8664-51 (1998-2001). Benchmark Analysis. Project SMT4-CT97-2188 EU project.

19. Gally, M., GÜNEY, M. and RIEUTFORD, E. (1979). "An Investigation of Pressure Transients in Viscoelastic Pipes". J. Fluid Engng. ASME 101, 495-499.

20. Ghilardi, P. and Paoletti, A. (1986). "Additional Viscoelastic Pipes as Pressure Surges Suppressors". Proceedings of the 5th International Conference on Pressure Surges, BHRA, Cranfield, UK, pp. 113-121.

21. Hino, M., Sawamoto, M. and Takasu, S. (1977). "Study on the Transion to Turbulence and Frictional Coefficient in an Oscillatory Pipe Flow". Trans. JSCE 9, 282-285.

22. Loureiro, D. (2002). "The Influence of Transients in Characteristic Hydraulic and Water Quality Parameters”. MSc. Thesis, IST, Lisbon (in Portuguese).

23. Loureiro, D. and Ramos, H. (2003). "A Modified Formulation for Estimating the Dissipative Effects of 1-D Transient Pipe Flow”. In: PEDS (Pumps, Electromechanical Devices and Systems) Applied to Urban Water Management. IAHR/IWA, Valência, Spain. (Accepted in January 2003).

24. Pearsall, I.S. (1965). "The Velocity of Water Hammer Waves". Proceedings of the Institution of Mechanical Engineers, Vol. 180, Part 3E, Westminster, London, pp. 12-20.

25. Pejovic, S., Boldy, A.P. and Obradovic, D. (1987). Guidelines to Hydraulic Transients Analysis. Technical Press.

26. Pezzinga, G. (1999). "Quasi-2D Model for Unsteady Flow in Pipe Networks”. J. Hydraul. Engng. 125, 676-685.

27. Pezzinga, G. (2000). "Evaluation of Unsteady Flow Resistances by Quasi-2D or 1D Models". J. Hydraul. Engng. ASCE 126, 778-785.

28. Pezzinga, G. (2002a). "Discussion of 'Developments in Unsteady Pipe Flow Friction Modeling”. J. Hydraul. Res. IAHR 40, 650-651.

29. Pezzinga, G. (2002b). "Unsteady Flow in Hydraulic Networks with Polymeric Additional Pipe". J. Hydraul. Engng. ASCE 128(2), 238-244.

30. Pezzinga, G. and ScAndura, P. (1995). "Unsteady Flow in Installations with Polymeric Additional Pipe". J. Hydraul. Engng. ASCE 121, 802-811.

31. Ramos, H. (1986). "Mathematical Models to Simulate Open Channel Flows". MSc Thesis, Technical University of Lisbon, IST, Portugal (in Portuguese).
32. Ramos, H. (1995). "Simulation and Control of Hydrotransients at Small Hydroelectric Power Plants". PhD Thesis, Technical University of Lisbon, IST, Portugal (in Portuguese).

33. Ramos, H. and AlmeidA, A.B. (2001). "Dynamic Orifice Model on Waterhammer Analysis of High or Medium Heads of Small Hydropower Schemes". J. Hydraul. Res. IAHR 39(4), 429-436.

34. Ramos, H. and Loureiro, D. (2002). Evaluation of the Influence of Transients in the Energy Dissipation of Pipe Flows (in Portuguese: Avaliação da influência dos regimes transitórios na dissipação de energia em escoamentos em pressão). LHRH-DEC, IST.

35. Rieutford, E. and Blanchard, A. (1979). "Ecoulement Non-permanent en Conduite Viscoelastique-Coup de Bélier”. J. Hydraul. Res. IAHR 17(1), 217-229.

36. Silva-Araya, W.F. and Chaudhry, (1997). "Computation of Energy Dissipation in Transient Flow". J. Hydraul. Engng. ASCE 123(2), 108-115.

37. TrikHA, A.K. (1975). "An Efficient Method for Simulating Frequency-dependent Friction in Transient Liquid Flow". J. Fluids Engng. Trans. ASME 97(1), 97-105.

38. VARDY, A.E. and Brown, J. (1995). "Transient, Turbulent, Smooth Pipe Friction". J. Hydraul. Res. 33(4), 435-456.

39. VARDY, A.E. and Brown, J. (1996). "On Turbulent, Unsteady, Smooth-pipe Friction". Proceedings of the 7th International Conference on Pressure Surges and Fluid Transients in Pipelines and Open Channels. BHR Group Ltd., Harrogate, England, UK, pp. 289-311.

40. VARDY, A.E. and HwANG, K.L. (1991). "A Characteristic Model of Transient Friction in Pipes". J. Hydraul. Res. Delft, The Netherlands 29(5), 669-685.

41. VArdy, A.E., Hwang, K.L. and Brown, J.M.B. (1993). "A Weighting Function Model of Transient Turbulent Pipe Friction”. J. Hydraul. Res. Delft, The Netherlands 31(4), 533-548.

42. Vitkovsky, J., Lambert, M. and Simpson, A. (2000). "Advances in Unsteady Friction Model in Transient Pipe Flow". Proceedings of the 8th International Conference on Pressure Surges (AnDREson, A., ed.) The Hague, pp. 471-498.

43. Wylie, E.B. and Streeter, V.L. (1993). Fluid Transients in Systems. Prentice Hall, Englewood Cliffs, NJ.

44. ZeILKE, W. (1968). "Frequency-dependent Friction in Transient Pipe Flow". J. Basic Engng. Trans. ASME Series D 90(1), 109-115. 